\title{
CORRECTIONS
}

\section{Zinc deficiency in a premature infant}

In this Minerva picture story the corresponding author's email address contains a typo (BMJ 2013;346:e8642, doi:10.1136/

Cite this as: BMJ 2013;346:e8671

bmj.e8642). R N Matin's email address is

๑ BMJ Publishing Group Ltd 2013

rnhmatin@doctors.org.uk (not rnhmatin@doctors.ork.uk). 